\title{
Toward Successful Integration of Climate Immigrants: Lessons Learned from the Good Practice of the City of Vienna
}

\author{
Ryo Fujikura, Shams Asadi, Laura Kraus, and Mikiyasu Nakayama
}

\begin{abstract}
Climate change will force people to move across national borders. This study analyzes the experience of the City of Vienna. While the federal government has continuously adopted less tolerant policies for immigrants, the City of Vienna has accepted them with firm political initiative. It has implemented various measures to effectively include immigrants into the society in cooperation with many stakeholders. In particular, "Integration from day one" and Start Coaching Vienna are unique attempts to help immigrants to promptly adapt to the society. Local governments will have to accommodate people when they are forced to immigrate due to climate change. Integrating them will be one of the most important adaptation measures for local governments. Experiences of the City of Vienna provide useful lessons for local governments.
\end{abstract}

Index Terms - Climate change, immigrant, refugee, Vienna, integration.

\section{INTRODUCTION}

A worldwide concern is the huge number of displaced people due to adverse effects of climate change including not only extreme weather, flooding, drought or rising sea levels but also armed conflict caused by the effects. Migration is traditionally caused by several drivers such as social, political, and/or economic factors, and in modern times climate is becoming a driver that too accelerates migration. There are no robust global estimates of the future displacement, but significant evidence shows that extreme weather events increase human displacement and the security costs. For example, 17 million people were displaced by natural hazards in 2009 and 42 million in 2010 [1]. Compared to 2000 , there may be between 114 and 192 million additional people living in floodplains in urban areas in Africa and Asia by 2060, respectively [2]. A $0.5 \mathrm{~m}$ sea level change implies a likely land loss of 0.877 million $\mathrm{km}^{2}$ by the year 2100, displacing 72 million people, with no adaptation investment; with a $2.0 \mathrm{~m}$ sea level change, 1.789 million $\mathrm{km}^{2}$

Manuscript received January 15, 2019; revised March 24, 2019. This work was supported by JSPS KAKENHI Grant Numbers JP16H03320, JP17K18590, and by the Graduate School of Frontier Sciences of the University of Tokyo.

R. Fujikura is with Faculty of Sustainability Studies, Hosei University, Tokyo, Japan (e-mail: fujikura@hosei.ac.jp).

A. Shams is with the Human Rights Office of the City of Vienna Menschenrechtsbüro, Wien, Austria (e-mail: shams.asadi@wien.gv.at).

Laura Kraus is with Austria Fellow, Menschenrechtsbüro, Wien, Austria (e-mail: laurakraus93@yahoo.com).

Mikiyasu Nakayama is with the University of Tokyo, the Department of International Studies, Graduate School of Frontier Sciences, Chiba, Japan (e-mail: nakayama@k.u-tokyo.ac.jp). would be lost, displacing 187 million people, or $2.4 \%$ of global population, mostly in Asia [1]. Populations of small islands in the Pacific and Indian Ocean are estimated to increase to 65 million by 2050 and will be seriously affected by rising sea levels [3].

While climate migration is expected to intensify toward 2050 , it can be a sensible adaptation strategy if the migration is managed carefully and supported by good development policies and targeted investments [4]. It does not only present a challenge to cities and society, but also an opportunity for enrichment. The benefit of migrants in OECD countries include a significant increase of the working-age population, filling important niches in labor markets, as well as higher tax revenues and social contributions than benefits claimed [5].

There are a number of arguments addressing the legal recognition of migrants displaced by climate change moving across national borders. They may not be recognized as "refugees" according to the existing legal framework. The 1951 Convention Relating to the Status of Refugees defines refugees as internationally displaced people due to humanitarian crisis. Those displaced by climate change will not be recognized as refugees unless climate change results in armed conflict or well-founded fear of persecution. For example, many people and organizations asserted that the Syrian civil war was caused by climate change. However, Reference [6] argue that there is no clear and reliable evidence that climate change and its impact, namely drought, caused the civil war.

On the other hand, a few studies address how migrants should be accommodated in a destination country. Reference [7] identified that the interval between the occurrence of a disaster and the decision of the people to leave their home depends on the type of disaster. While the decision to flee due to rising sea levels can take years, extreme weather or flooding may force victims to decide to move within a few days. As the intensity of extreme weather is forecasted to increase, the risk of sudden mass evacuation will be further intensified by climate change. A massive flow of migrants must be dealt with within a short period of time at their destination. Otherwise, huge numbers of migrants will face difficulty to find an appropriate place to stay resulting in a deterioration of security and the living environment at the destination. Measures to properly and quickly accommodate the vast number of migrants must be established before the adverse impacts of climate change become significant.

The City of Vienna, one of the federal provinces of the Republic of Austria, as well as the federal capital city and the largest municipality with a population of $1,888,776$ as of January 2018, has a unique experience of quick resettlement 
and positive integration and social inclusion of migrants into society. After World War II, a large number of migrants from Eastern Europe rushed to Vienna on several occasions. A similar situation can currently be observed with persons fleeing from the Middle East and South Western Asia. The city has successfully managed this influx. In 2015, 88,098 individuals applied for asylum in Austria, which is equivalent to $1 \%$ of the Austrian population [8]. Vienna has historically gained various working knowledge in addressing the needs of asylum seekers and recognized refugees.

This paper introduces Vienna's policy and management of immigrants, particularly its quick measures to accommodate asylum seekers until they obtain refugee status and to integrate immigrants including refugees into society. It first briefly reviews the history of immigration to Austria and summarizes Vienna's immigrant policy and integration measures. Then, it examines Vienna's measures using an analytical framework proposed by reference [9]. Lastly, the applicability of Vienna's experience to future accommodation and integration of climate migrants is discussed.

In this paper, the term "immigrants" does not only include people voluntary moving to a country across national borders but also involuntary and internationally displaced persons such as evacuees, asylum seekers and recognized refugees. From a human rights perspective it is preferable to speak of "inclusion" rather than "integration". Integration is the process of placing outsiders into existing mainstream processes whereas inclusion involves structural changes in society to equally accommodate everyone, fostering participation. In this paper, however, we use the term "integration" because we are focusing on the urgent need of accepting immigrants rather than long-term measures aiming at structural change.

\section{HistORY OF IMMIGRATION TO AUSTRIA}

Austria covers an area of 84,000 square kilometers and has a population of 8.8 million people. As it was located adjacent to the "Iron Curtain" during the Cold War, a large number of evacuees fled to the country. The number of evacuees resulting from the Hungarian uprising in 1956 and Prague Spring in 1968 reached 180,000 and 160,000, respectively. After the Cold War ended, 115,000 evacuees fled due to the collapse of Yugoslavia from 1991 to 1993, and many escaped to Austria from conflicts in Kosovo (1998-2000) and Chechnya (2001-2003) [10].

A quick response by Austria could be seen during the Hungarian uprising. In the last week of October 1956, thousands of Hungarians fled to Vienna, which had not yet recovered from devastations of the war. On the $4^{\text {th }}$ of November, the Austrian Minister of the Interior sent urgent cable to the UNHCR and Inter Governmental Committee for European Migration requesting emergency measures. Evacuees were quickly transported to Vienna, where they were registered and sent to accommodation facilities. Until the $31^{\text {st }}$ of December 180,000 of 200,000 evacuees in Austria and Hungary were accepted by 37 countries around the world Only 410 Hungarians settled in Austria by June 1959. The largest host country was the United States accepting 40,650

\section{Hungarians [11].}

From the early-1960s to the mid-1970s, a large number of "guest workers" (Gastarbeiter) immigrated from Turkey and former Yugoslavia to meet the employment demand in Austria like in other western European countries. After the oil crisis in 1973 and following economic stagnation, while most former Yugoslavian workers returned home, most Turkish people opted to stay in Austria and reunified their families. The proportion of Turkish residents in Austria increased from 7.7 percent of all foreigners in 1971 to 22.2 percent in 2001 [12].

Despite the long history of migration, integration was not regarded as a political issue in Austria. Until 1987, immigration was only recognized as a labor issue, and the federal government recognized integration as cultural assimilation. As the influx of immigrants drastically increased in the early 1990s, immigration finally became a political issue. In 1997, the new Aliens Act was formulated to strengthen control over immigrants and immigration. The Act was later amended to further strengthen immigrant control. All new immigrants from non-EU countries are required to attend an "integration course" and learn the German language and Austrian laws, culture and history [12]. The Austrian federal government recognized itself as "not being a country of immigration." Immigrant integration was only institutionalized in 2011 with the establishment of a State Secretariat for Integration in the Ministry of Interior. In 2002, the Act was amended and immigrants expecting to stay in Austria were required to sign a so-called "integration agreement." This also required a basic level of knowledge of the German language within a certain period. The Act was further amended in 2005 and 2011, making the requirements to the immigrants progressively more stringent [13]. In 2016, the Act and other related acts were amended further to restrict immigration by making the country "less attractive" for immigrants [14]. In 2017, Sebastian Kurz was elected as Chancellor and he firmly opposed the EU refugee quota (Flüchtlingsquote), insisting to strengthen border controls.

\section{DIVERSITY POLICY OF VIENNA}

Integration policies of the Vienna Municipal Government (hereafter 'Municipal Government") have always differed substantially from that of the federal government. The Municipal Government has a prominent voice in debates on integration and migration, and has developed its own integration policy with its welcome culture. It defined integration as the incorporation of all sections of the population into central domains of society and their active participation in these domains [15]. The Municipal Government already established the "Migrants Fund" as early as 1971 for providing affordable housing for their first year of stay both for internal and international (mostly from the former Yugoslavia and Turkey) migrant workers [16]. Following the collapse of Yugoslavia and the regime changes in Eastern Europe since 1989, it established the "Funds for Integration" in 1992, as the very first government-funded institution in Europe tasked exclusively with integrating international migrants [16]. Recognizing significant responsibility for the realization of human rights, it hosted the 
United Nations World Conference on Human Rights organized by the United Nations Human Rights in 1993, which adopted the Vienna Declaration and Programme of Action. The declaration stresses the promotion and protection of human rights including that of migrant workers [17].

In 2004, the Municipal Government dissolved the Fund for Integration and established the Municipal Department of Integration and Diversity (MA17), which plays a central role in the integration of immigrants into the city [16]. It shows that integration and diversity issues were integrated into the daily work of the municipal administration. In a 2007 report Vienna presented its approach to integration: "Integration is an asymmetrical and mutual process which aims at increasing equal access and participation by eliminating barriers, fighting discrimination, and promoting strategies of empowerment. At the same time, immigrants should be invited, encouraged and motivated to contribute to individual and social advancement by overcoming everyday difficulties despite their comparatively disadvantaged starting point" [13]. In 2007, the Municipal Government commenced the implementation of its Integration and Diversity Monitoring scheme, a tool which enables the ongoing monitoring of the level of integration among Vienna's residents by means of indicators and illustrates the quality of the city administration's diversity management efforts by conducting an online survey of municipal departments and institutions in Vienna. The $4^{\text {th }}$ Diversity Monitor published in November 2017 also includes a brief section on the issues of refuge and asylum and analyses Vienna's integration and diversity efforts in the past ten years [18].

In November 2012, based on comprehensive input with 8,500 participants and more than 47,000 contributions submitted, the Municipal Government adopted "The Vienna Charter" (Wiener Charta), aiming "to set the course for a good and respectful climate in our City in cooperation with all our citizens" [19]. While the other Austrian provinces and municipalities refused to accept a nationally assigned quota of asylum seekers, Vienna alone fulfilled it [20]. In fact, Vienna exceeded the quota of 5,578 persons by 3,894 persons (reaching 8,877 persons) in 2004 , by 1,897 persons (reaching 7,475 persons) in 2005 and by 1,438 persons (reaching 7,016 persons) in July 2006 [21].

In December 2014, the Municipal Government further passed the declaration "Vienna - City of Human Rights" enabling a human rights-based approach on all governmental levels of the city. As an experienced city on migration, integration and diversity management, the Municipal Government is determined to further advance its cross-cutting human rights-based approach through additional inclusionary measures. With this Declaration, Vienna "pledges to act as a guardian and defender of human rights by striving to respect, protect and be accountable for human rights in all of its areas of competence" [22].

An important step in this process was the establishment of the Human Rights Office in autumn of 2015. It works together with political and governmental entities, as well as NGOs and civil society, both on a local and an international level to implement the City Council's declaration and to guide further development of the Human Rights Culture in Vienna. In its cooperation, the Municipal Government focuses on raising awareness about human rights, issues of children's rights such as unaccompanied refugee minors, fighting poverty and violence, security policies and human rights at the federal level, and awareness raising and undertaking measures towards combating of human trafficking.

When more than one million asylum seekers arrived in Europe totaling 89,127 mostly from Syria and Afghanistan, in Austria, the right-wing populist parties obtained support of over $30 \%$ in the national opinion polls and fueled a climate of fear. Even mainstream parties aligned themselves more and more with this populist position. However, the Municipal Government, a coalition of the Socialist (SPÖ) and Green parties as well as Austria's then-President (also SPÖ) stood out in this counter discourse [23].

Vienna is becoming a minorities' majority city. At the beginning of 2016, it had 1,840,226 inhabitants, and 50 per cent of them had a migration background, which means that they themselves or at least one of their parents were born abroad or have foreign nationalities. The share of foreign nationals increased from 13 per cent in 1991 to 27 percent in 2016 [16]. In 2018, 38\% of its residents were born outside Austria or hold a foreign passport.

\section{INTEGRATION MEASURES OF THE MUNICIPAL GOVERNMENT}

All asylum seekers in Austria are transferred to a refugee camp in Traiskirchen upon their arrival, and are later transferred to one of the Provinces (Bundesländer). They apply for asylum status at the Federal Office for Immigration and Asylum, (BFA: Bundesamt für Fremdenwesen und Asyl), an organization of the Ministry of the Interior. When they are granted a temporary stay in Austria, a permit of provisional stay (Aufenthaltsgenehmigung) is issued. Those who are issued this permit must immediately register at the federal Labor Market Service (AMS: Arbeitsmarktservice), where job information is provided.

\section{A. The Key Players in Charge and Responsible for Refugees}

In Vienna, the Municipal Department for Integration and Diversity (MA 17) cooperates not only with other departments of the City but also with many other organizations such as the Chamber of Labor Vienna, the Vienna Employment Promotion Fund, and NGOs. One of the key players is the Vienna Social Fund (FSW-Fonds Sociales Wien). The FSW was established under auspices of the Municipal Government in order primarily to take care of the elderly, people with disabilities and homeless people. It also works to meet the needs of asylum seekers and immigrants requiring assistance. It provided around 21,000 asylum seekers with assistances in 2015 [24]. The activities were based on the previous experiences to meet the needs of asylum seekers and recognized refugees. For example, it developed a registration system to issue an ID card, which facilitates the access to health and logistics services [25].

One of the objectives of the integration policy is to support asylum seekers from the first day of arrival up to their integration into society without system discontinuities. An 
initiative of "Integration from day one" formulated by the Municipal Government and jointly implemented by MA17 and the FSW has become the keynote of Vienna addressing the issue of asylum seekers. Asylum seekers transferred to Vienna can exclusively benefit from various needs-based services including education counselling, estimates on competences, language courses, provision of basic education, and guidance for further education [25].

The MA 35 (Immigration and Citizenship) of the Municipal Government is authorized to implement the Aliens Act. Once the asylum seekers have registered at the MA 35, they are able to benefit from Start Coaching Vienna (Start Wien). This is an initiative operated by MA17 to support newcomers as quickly as possible. MA 17 officers provide them with individual counseling in 25 different languages regarding necessary information such as learning German, working, housing, health care, legislation, etc.

\section{B. Education}

Asylum seekers of compulsory school age (up to 15 years old) participate in education at primary or secondary schools. It was realized when the number of asylum seekers increased that no "system" existed to educate them over 15 years old. They first of all needed German language skills to the level of $\mathrm{B} 1$, which is mandatory for any further training or education towards securing jobs [16]. In order to fill the gap, the "Youth College" was established based on the experiences of Vienna gained in addressing the influx of migrants from Central and Eastern European member states of the European Union after the latest EU-enlargements in 2004 and 2007. The "Vocational Training Guarantee" was formulated in 2010 aiming at providing young people (14 to 21 years old) with the opportunity to receive education towards formal qualifications. Various organizations such as the Vienna Board of Education, the Public Employment Service, the Federal Social Welfare Department took part in this endeavor [26].

\section{Mental Support}

Asylum seekers arriving in a foreign country tend to have such predisposing factors as separation from family, loneliness in the host community, lack of language skills, and lost socio-economic status in the home country [27]. According to a survey carried out in Vienna, half of the asylum seekers in fall 2015 lost a family member after leaving their own countries [8]. It is thus important to consider the mental wellbeing and past traumas of asylum seekers, so that their pain may be mitigated or resolved in preparation for their re-establishing livelihood in the host community. There are more than 100 facilities in Vienna, such as Vienna Integration House (Integrationshaus Wien), providing basic care support for asylum seekers to reestablish their daily life, including German courses, counselling, and provision of information and opportunities of non-profit work. There is an extensive funding network including FSW funding to support the activities. The FSW funds 9 facilities operated by NGOs for people who need mental support.

\section{Housing}

Once asylum seekers obtain refugee statues, they have to evacuate from temporary housing for asylum seekers within
4 months. Due to the increase of housing costs in Vienna, like other metropolitan areas in Europe, finding housing becomes an increasingly difficult task. They tend to be concentrated in some certain places in the city resulting in residential segregation. This is one of the potentially troubling side effects of urbanization and large-scale immigration, hindering integration of the migrants. In Vienna, the share of public housing is high and $63 \%$ of the Viennese population lives in social housing or in public subsidized dwellings. In 2001 , there were 168,872 buildings in Vienna, and $15.8 \%$ $(26,733)$ of them were owned by local authority, and $9.3 \%$ $(15,741)$ were owned by housing associations most of which belong to the Municipal Government [21]. Utilizing public facilities, the Municipal Government has been keeping residential segregation at a relatively low level. There are various indices presenting residential segregation, and a dissimilarity index is one of the most commonly used. This index ranges from zero to 100 , with higher numbers indicating more segregation. Dissimilarity scores over 60 are high in absolute terms, those from 30 to 60 are moderate, and those below 30 are low. That of Vienna regarding foreigners remains 30 [28].

In 2015/2016 the Municipal Government rapidly created 8,000 additional places in emergency shelters in reaction to the increase of asylum seekers. Regarding the management of temporary emergency accommodation, the Municipal Government (FSW and Head Office for Basic Provisions for Persons Seeking Protection and Asylum) cooperating with NGOs utilized vacant buildings belonging to the Municipal Government and additionally rented private property to accommodate asylum seekers. The aim is to avoid urban concentration of refugees, and the focus is on flat-sharing communities with three or four people per flat. At the same time, an appeal was published to the population to donate housing for this purpose. At the end of the year 2016, 63 per cent of the 20,500 asylum seekers receiving basic welfare support in Vienna resided in private accommodations and 37 per cent were hosted in 90 organized shelters. For recognized refugees, a provision of housing is possible under certain circumstances (via the Counselling Center for the Homeless "bzwo" run by FSW), otherwise they have to rely on the housing market or on private help via the support of specialized NGOs. FSW possesses around 6,500 flats in 100 locations in the city for homeless persons and allows refugees to stay there for 2 years.

\section{E. Volunteering of Second and Third Generations}

Many second or third generation descendants of refugees from former Eastern European countries, volunteered to assist asylum seekers from Syria in 2015 and thereafter, in return for the hospitality their parents or grandparents had received from the people of Austria. It implies that a positive cycle exists in Austria in which former asylum seekers and refugees serve as a part of the host community (i.e. Austrian society) to mitigate the difficulties which asylum seekers tend to feel initially towards their livelihood re-establishment.

\section{ANALYSIS OF INTEGRATION MEASURES}

All persons are inherently entitled to human rights, without 
discrimination, by virtue of their status as a human being. As stated in Article 1 of the Universal Declaration of Human Rights: "All human beings are born free and equal in dignity and rights." The right to seek asylum is a right entrenched in international human rights law. Article 14 of the Universal Declaration of Human Rights states that "Everyone has the right to seek and to enjoy in other countries asylum from persecution." The United Nation as 1951 Convention Relating to the Status of Refugees and its 1967 Protocol specifically deal with this human right and guide national legislators on the topic. In order to respect human right of immigrants, integration into the host community is indispensable.

There is no consensus on the definition of immigrant integration nor agreement on what is considered "successful" integration. We, therefore, utilize an analytical framework, "Indicators of Integration" developed by Reference [9] to examine the effectiveness of measures of the Municipal Government. The framework consists of four domains: Means and markers, Social connections, Facilitators, and Foundation. The first domain, Means and markers includes four indicators: Employment, Housing, Education and Health. The second domain, Social connections includes three: Social bonds, Social bridges and Social links. The third domain, Facilitators includes two: Languages and cultural knowledges and Safety and stability. The fourth domain, Foundation includes one: Rights and citizenship.

\section{A. Means and Markers}

"Start Coaching Vienna" is a tool for substantial contribution toward the improvement of the four indicators of means and markers.

Regarding Employment, the Vienna Employment Promotion Fund (WAFF), an organization under the auspices of the Municipal Government, takes part in the Vienna Start Coaching and provides a module including first consultation concerning the labor market and job opportunities. The "Vocational Training Guarantee" is an initiative to provide young people with the education for securing jobs. To integrate refugees who have not yet obtained their legal residence permit or asylum status the FSW started a welfare-job program for refugees. The Human Rights Office hosted a young man from Syria to include him into the daily work at the office and provide an opportunity to experience a Viennese business environment.

As for Housing, Vienna is one of the world's pioneers, with more than 220,000 flats called "Gemeindebau," which are council housing erected by the Municipal Government to provide affordable public housing or subsidized apartments. A large number of municipality-owned houses also contributed, and the information on housing is provided through Start Coaching Vienna. The international building exhibition (Internationale Bau-Ausstellung), will take place in Thüringen in 2019 and then in Vienna in 2022. It is about social housing policy as well as focusing on the construction of new buildings, but will be coined by a commitment to innovation and dealing with neighborhoods in all their facets under the moto "Living Together". It will include Viennese people of all generations and backgrounds throughout the entire process, reflecting Vienna's open and diverse society.
Education is one of the central measures for immigrant integration. One of the unique measures in Vienna is the Youth College which also contributes to Employment of young migrants. It should be noted that the Municipal Government and NGOs are paying special attention to the mental health of asylum seekers. The "integration from day one" program mitigates the anxiety of newly arrived people, and the nine facilities are providing mental health care for asylum seekers. ID cards are issued by FSW for asylum seekers to facilitate access to health and logistics services. More than 40,000 newcomers arrived in Vienna in 2017. At present, inclusion for children up until the age of 15 is ensured by mandatory school attendance. Diverse backgrounds can be a challenge for schools and teachers who are sometimes ill-equipped for the situation, but the Municipal Government has mixed classes to ensure faster integration rather than to single out migrant and refugee children. The Human Rights Office together with the Department for Integration and Diversity, works in close collaboration with the school authorities (e.g. Stadtschulrat) as well organizing help and support from native speakers.

\section{B. Social Connections}

Social connections are indispensable to mitigate their anxiety, make them feel better, lower feelings of isolation and depression, and increase their motivation to help each other.

Social bonds are relations among immigrants, by which they communicate in their own language, maintain their own custom and culture, and share information regarding their new life. Churches and mosques are important places where immigrants meet and communicate. FSW owned nine facilities accepting asylum seekers and Youth College provided opportunities to establish such social bonds.

Social bridges are relationships between immigrants and the host community, a fundamental factor necessary for "two-way" integration. Small acts of friendship such as being recognized and greeted by neighbours are crucial for migrants to feel "at home." During the period of "welcoming culture" of summer and autumn 2015, many asylum seekers experienced a positive atmosphere and felt encouraged by simple communication with local people [8]. NGOs play a key role in establishing the social bridge through various measures such as education, events, or field activities [29].

Social links refer to the connection between individuals and structures of the state, such as government services. As described above, the Municipal Government provides various services. It should be noted that many asylum seekers were astonished by and appreciative of the friendly and cooperative approach of police, compared to generally oppressive police in their home countries [8].

\section{Facilitator}

Since German language skills are a fundamental requirement of the federal government for immigrants to be integrated, many stakeholders including the Municipal Government and NGOs are making every effort to provide these language skills. One of the major activities of Start Coaching Vienna is provision of information of language courses for immigrants. Newcomers to Vienna are offered advice regarding where to find suitable language courses. 
Safety and stability are acquired through obtaining linguistic capability, education, housing and employment.

\section{Foundation}

A major focus of the Human Rights Office has been unaccompanied refugee minors. Cooperating with other municipal departments, public institutions, NGOs, civil society initiatives, and experts, the office is concentrating its efforts to raise awareness for human rights. Many feel abandoned when they obtain refugee status. Through participation of various integration programmes, refugees renew their self-confidence, and start to feel a sense of belonging. The Municipal Department 11 of the City of Vienna, the Youth and Family office, has also taken various initiatives to facilitate the inclusion of refugees and asylum seekers. Such initiatives include a buddy system, services for accompanying of youths to interviews and appointments; and the education and awareness raising of governmental bodies.

\section{DISCUSSION}

Climate change is a factor that may force people to move in various way. As for lowlands, sea-level rise, storm surges, floods, and invasion of sea water into groundwater will displace people. Drought will be a major factor in arid and semi-arid areas. Furthermore, although no definite cause-and-effect relationship has been confirmed, a local conflict might be triggered by the environmental deterioration and displace people. As a result, migration patterns will also vary depending on the causes.

Migration is either temporary or permanent. People will return to the original land if local adaptation is effectively implemented and original land is, at least partially, secured. It is the case that the risk of flood is lowered by infrastructure improvement or that the risk of drought is lowered by irrigation facilities. In the case of a conflict, political solution will encourage people to return. Thus, the migration likely becomes temporary. On the other hand, in the case of the submergence due to sea level rise, people can no longer return to the original land and the migration becomes permanent.

Intensity of the movement will also be different. Natural disaster including flood and storm or conflict forces a large number people to evacuate within a short period of time. In the case of land submergence, drought, sea water intrusion or desertification, people may gradually immigrate over a long period of time.

It can be concluded that people likely stay only temporarily and return to the original land in cases of intensive migration. On the other hand, gradual migration will likely result in permanent relocations. Therefore, relocation can be roughly categorized into short-term reversible and long-term irreversible. In the short-term and reversible cases, institutions and facilities temporarily accepting immigrants is crucial. That is Foundation, an indicator proposed by Reference [9], and it is national government which formulate and implement measures to handle the people who enter their borders. On the other hand, in the long-term and irreversible case, the other three indicators (Means and markers, Social connections,
Facilitators) are important. In the case of Vienna, while Foundation is mainly provided by the federal government, the latter is effectively provided by the Municipal Government. It should be noted that "Integration from day one" and Start Coaching Vienna, Vienna's unique approaches, have been contributing to effectively and smoothly integrated migrants after they are transferred to Vienna by the federal government.

In Austria since 2015, the federal government has been adopting intolerant policies towards refugees, as right wing and populist politicians and mass media were fuelling antipathy toward immigrants, and citizens were becoming less intolerant. There were once 300 host families accommodating immigrants in Vienna, but the number reduced to 20 households in 2018. However, the Municipal Government continues to take a policy to pursue diversity. Politicians of Vienna have been keeping a firm consciousness and accepting immigrants. Temporary or permanently, local governments will have to accommodate people when they are forced to immigrate due to climate change. The role of local governments will become increasingly important. Integration of them will be one of important adaptation measures for the local governments. The City of Vienna's experience as a local government provides many useful lessons as anticipation of an increase in climate immigrants.

\section{ACKNOWLEDGMENT}

The authors wish to express their gratitude for the staff members of the Vienna Social Fund, who kindly contributed many hours out of their very busy working hours. Since many of them expressed their personal opinions rather than as staff members of the organization, they should be left anonymous for this study. The authors also thank refugees living in Vienna for accepting the interviews. Upon their request, they will remain anonymous for the purpose of the study. The authors also appreciate Ms Mag. Noriko Weiß for her support during the interviews. All of them made invaluable contributions through the development of this article.

\section{REFERENCES}

[1] IPCC, Chapter 12 Human Security, Climate Change 2014: Impacts, Adaptation, and Vulnerability, p.768, 2014.

[2] Foresight, Migration and Global Environmental Change, The Government Office for Science, London, U.K., 2011.

[3] J. Barnett and M. Webber, "Accommodating migration to promote adaptation to climate change," Policy Research Working Paper 5270 The World Bank, Washington D.C., USA, 2010.

[4] World Bank, Groundswell: Preparing for Internal Climate Migration, p. XXIV, The World Bank, Washington D.C., USA, 2018.

[5] OECD, "Is migration good for the economy?" Migration Policy Debates, May 2014, OECD, Paris, France, 2014.

[6] J. Selby, O. S. Dahi, C. Froehlich, and M. Hulme, "Climate change and the Syrian civil war revisited," Political Geography, vol. 60, pp. 232-244.

[7] M. Nakayama, N. Yoshioka, H. Fujibayashi, and C. Bruch, "Factors affecting livlihood re-establishment of climate change induced transboundary displaced persons," International Journal of Social Science Studies, vol. 4, no. 9, pp. 40-48, 2016.

[8] J. Kohlenberger, I. Buber, B. Rengs, and Z. Al Zalak, „A social survey on asylum seekers in and around Vienna in fall 2015: Methodological approach and field observations (No. 6/2016)," Vienna Institute of Demography Working Papers, 2016.

[9] A. Ager and A. Strang, "Understanding integration: A conceptual framework," Journal of Refugee Studies, vol. 21, no. 2, pp. 166-191, 2008 . 
[10] F. S. Wien, Flüchtlinge, Asyl und Grundversorgung, Vienna, Austria, 2017.

[11] UNHCR, "Fifty years on, refugees," no. 144, pp. 2-23, UNHCR, Geneva, Switzerland, 2006.

[12] J. Wets, "The Turkish community in Austria and Belgium: The challenge of integration," Turkish Studies, no. 1, pp. 85-100, 2006.

[13] J. M. Permoser and S. Rosenberger, "Integration policy in Austria chapter 2 pp. 39-58," International Perspectives: Integration and Inclusion, McGill-Queen's University Press, Montreal and Kingston, Canada, 2012.

[14] F. Watanabe, "Acceptance of refugee by Germany, Austria and Hungary (in Japanese)," Gaikoku no Rippou, vol. 272, pp. 50-61, 2017.

[15] UNHCR. (2013). A New Beginning: Refugee Integration in Europe. [Online]. Available: http://www.refworld.org/docid/522980604.html

[16] OECD, Integrating Migrants in Cities: Case Study Vienna, OECD, Paris, 2017.

[17] OHCHR, Vienna Declaration and Programme of Action, United Nations Human Rights Office of High Commissioner, 2018.

[18] S. Wien, Monitoring Integration Diversität Wien 2013-2016, Cicy of Vienna, Austria, 2017.

[19] S. Wien, Winer Charta, Cicy of Vienna, Austria, 2013.

[20] ORF. (2014). Asyl: Nur Wien hält Quote ein. [Online]. Available: https://oe1.orf.at/artike1/362964

[21] Cities for Local Integration Policy, Housing and Segregation of Migrants, Case Study: Vienna, Austria, European Foundation for the Improvement of Living and Working Conditions, Dublin, Ireland, 2009.

[22] City of Vienna, Declaration: Vienna - City of Human Rights, December 2014.

[23] M. Rheindorf and R. Wodak, "Borders, fences, and limits - Protecting Austria From refugees: Metadiscursive negotiation of meaning in the current refugee crisis," Journal of Immigrant \& Refugee Studies, vol. 16, no. 1-2, pp. 15-38, 2018.

[24] M. Langwiesner, "Action for inclusion in Europe city working groups homelessness and destitution amongst excluded migrant, centre on migration, policy and society," University of Oxford, Oxford, U.K., 2016.

[25] Eurocities, EUROCITIES: Cities' Actions for the Education of Refugees and Asylum Seekers, January 2017, EUROCITIES, Brussels.

[26] K. Zelano, G. Bucken-Knapp, J. Hinnfors, and A. Spehar, WP3 Comparative Report: Urban Governance of CEE mobility in European urban regions, IMAGINATION Project, March 2016, University of Gothenburg, Sweden.

[27] R. Tribe, "Mental health of refugees and asylum-seekers," Advances in Psychiatric Treatment, vol. 8, no. 4, pp. 240-247, 2002.

[28] J. Iceland, Residential Segregation: A Transatlantic Analysis, Migration Policy Institute, Washington, D.C., USA, 2014.

[29] S. Jong and I. Ataç, "Demand and deliver: Refugee support organisations in Austria," Social Inclusion, vol. 5, no. 3, pp. 28-37, 2017.

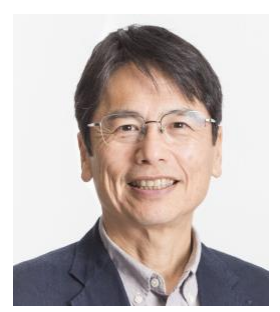

Ryo Fujikura obtained a doctor of natural science from Innsbruck University, Austria in 1982, and a master of science from the University of Tokyo in 1980. He is professor of Faculty of Sustainability Studies, Hosei University, Tokyo, Japan. He co-edited with Dr. Masato Kawanishi "Climate Change Adaptation and International Development: Making Development Cooperation More Effective" (London, UK: Earthscan, 2010), with Dr. Tomoyo Toyota "Climate Change Mitigation and International Development Cooperation" (London, UK: Earthscan, 2012), and with Prof. Mikiyasu Nakayama "Resettlement Policy in Large Development Projects" (Oxford, UK: Routledge, 2015).

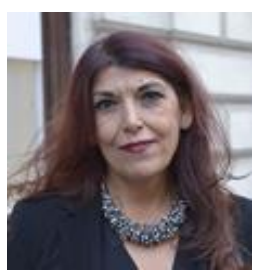

Shams Asadi is the human rights commissioner and head of the Human Rights Office of the City of Vienna. She studied architecture and urban planning abroad before she arrived in Vienna, where she graduated from the Vienna University of Technology. She has many years of practical and academic experience in Urban Regeneration and Urban Development with a focus on European and international affairs. The human rights dimension of urban development accompanied her from beginning of her professional life and since 2010 human rights are the main subject of her career.

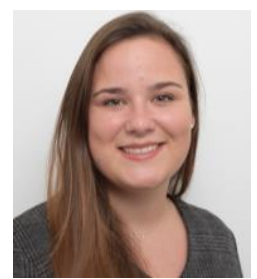

Laura Kraus is a teach for Austria Fellow, teaching at a local middle school in Vienna which is attended almost exclusively by children with migration background. She studied Economics and Law at the University of Cape Town and relocated to Vienna to pursue her MA in Human Rights at the University of Vienna. Throughout, and after her studies she held various leadership positions in student organisations focusing on education and completed internships at the Fundamental Rights Organisation and the Human Rights Office of the City of Vienna.

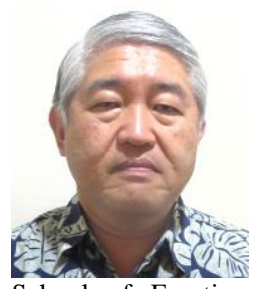

Mikiyasu Nakayama received his B.A. (1980), M.Sc. (1982) and Ph.D. (1986) from the University of Tokyo. He worked in the past for United Nations Environment Programme (UNEP), Utsunomiya University, World Bank and Tokyo University of Agriculture and Technology. From 2004, he has been a Professor of the University of Tokyo, in the Department of International Studies, Graduate School of Frontier Sciences. He co-edited with Prof. Ryo Fujikura "Resettlement Policy in Large Development Projects" (Oxford, UK: Routledge, 2015). 